\title{
SPECIES DIVERSITY, PHYLOGENY AND LARGE SCALE BIOGEOGRAPHIC PATTERNS OF THE GENUS PADINA (PHAEOPHYCEAE, DICTYOTALES) ${ }^{1}$
}

\author{
Thomas Silberfeld, ${ }^{2}$ Lucie Bittner
}

UMR 7138, UPMC, MNHN, GNRS, IRD: Systématique, adaptation, évolution, Département Systématique \& évolution, Muséum National d'Histoire Naturelle, 57 rue Cuvier, CP 39, 75231, Paris Cedex 05, France

\section{Cindy Fernández-García}

Programa en Botánica Marina, Posgrado en Ciencias Marinas y Costeras, UABCS, La Paz, México

Centro de Investigación en Ciencias del Mar y Limnología (CIMAR), Escuela de Biología, Universidad de Costa Rica, San Pedro, San José, 2060, Costa Rica

\section{Corinne Cruaud}

Genoscope, Centre national de séquençage, 2 rue Gaston Crémieux, CP 5706, 91057, Évry Cedex, France

\section{Florence Rousseau, Bruno de Reviers}

UMR 7138, UPMC, MNHN, CNRS, IRD: Systématique, adaptation, évolution, Département Systématique \& évolution, Muséum National d'Histoire Naturelle, 57 rue Cuvier, CP 39, 75231, Paris Cedex 05, France

\section{Frederik Leliaert}

Phycology Research Group, Ghent University, Krijgslaan 281, Building S8, 9000, Ghent, Belgium

Claude E. Payri

U227, Biocomplexité des écosystèmes coralliens de l'Indo-Pacifique, Institut de Recherche pour le Développement, BP A5, 98848,

Nouméa Cedex, New Caledonia

and Olivier De Clerck

Phycology Research Group, Ghent University, Krijgslaan 281, Building S8, 9000, Ghent, Belgium

The brown algal genus Padina (Dictyotales, Phaeophyceae) is distributed worldwide in tropical and temperate seas. Global species diversity and distribution ranges, however, remain largely unknown. Species-level diversity was reassessed using DNA-based, algorithmic species delineation techniques based on $\operatorname{cox} 3$ and $r b c \mathrm{~L}$ sequence data from 221 specimens collected worldwide. This resulted in estimates ranging from 39 to 61 putative species (ESUs), depending on the technique as well as the locus. We discuss the merits, potential pitfalls, and evolutionary and biogeographic significance of algorithmic species delineation. We unveil patterns whereby ESUs are in all but one case restricted to either the Atlantic or Indo-Pacific Ocean. Within ocean basins we find evidence for the vast majority of ESUs to be confined to a single marine realm. Exceptions, whereby ESUs span up to three realms, are located in the Indo-Pacific Ocean. Patterns of range-restricted species likely arise by repeated founder events and subsequent peripatric speciation, hypothesized to dominate speciation

\footnotetext{
${ }^{1}$ Received 14 January 2012. Accepted 10 July 2012.

${ }^{2}$ Author for correspondence: e-mail silberfeld@mnhn.fr.
}

mechanisms for coastal marine organisms in the Indo-Pacific. Using a three-gene (cox3, psaA and $r b c \mathrm{~L})$, relaxed molecular clock phylogenetic analysis we estimated divergence times, providing a historical framework to interpret biogeographic patterns.

Key index words: biogeography; brown algae; Dictyotales; general mixed yule-coalescent model; molecular phylogeny; Padina; Phaeophyceae; species delineation

Abbreviations: BI, Bayesian inference; BP, bootstrap support; cox3, cytochrome c oxidase subunit 3 gene; ESU, Evolutionarily Significant Unit; GMYC, general mixed yule-coalescent; ML, maximum likelihood; PP, Bayesian posterior probability; psaA, photosystem I P700 chlorophyll a apopotrein A1 gene; $r b c \mathrm{~L}$, large subunit of plastid-encoded ribulose-1,5-bisphosphate carboxylase oxygenase gene

Species of the genus Padina Adanson (Dictyotales, Phaeophyceae) are widely distributed in tropical and warm temperate seas, where they occur in intertidal and subtidal habitats, down to $100 \mathrm{~m}$ deep 
(N'Yeurt and Payri 2010). Padina is especially abundant in tropical regions where species may form extensive communities on reef flats and outer reef slopes (N'Yeurt and Payri 2006, Wichachucherd et al. 2010).

With 43 currently recognized species, Padina is the second most speciose dictyotalean genus after Dictyota (including 76 recognized species; Guiry and Guiry 2012, Ni-Ni-Win et al. 2008, 2010, 2011a). Padina species are peculiar in that they, together with Newhousia imbricata (Kraft et al. 2004), are the only brown algae known to display conspicuous calcification of the cell wall surfaces (Miyata et al. 1977, Borowitzka 1982, Okazaki et al. 1986, Salgado et al. 2011). This feature, along with the typical fan-shaped thallus makes the genus Padina easily recognizable in the field. Species identification, however, is less straightforward. It requires examination of a series of morphological and life-history traits, such as the location and degree of calcification, the number of cell layers, the location and disposition of hairlines and rows of tetrasporangial sori, or the monoecious versus dioecious nature of the gametophyte (Cribb 1951, Tanaka and Nozawa 1962, Umezaki and Yoneda 1962, Mshigeni and Mkwizu 1978, Womersley 1987, see Ni-Ni-Win et al. 2011a). Even when these characters are all available on a given specimen, species identification often remains ambiguous, because of subtle morphological differences between species and morphological plasticity of several characters under a variety of environmental factors, such as intertidal stress (Liddle 1975) or grazing (Diaz-Pulido et al. 2007).

Taxonomic studies of Padina were, until recently, exclusively based on morphological characters, and usually consisted of revisions or descriptions of new species in a given geographic area (e.g., Tanaka and Nozawa 1962, Gaillard 1975, Lee and Kamura 1991, Wynne 1998, Yoshida 1998, Ávila-Ortiz and Pedroche 1999, 2005, Wynne and De Clerck 1999, Yoshida et al. 2000, Abbott and Huisman 2003, Geraldino et al. 2005, Sun et al. 2008, RiosmenaRodríguez et al. 2009). More recently, a series of studies has approached species-level diversity in the genus, combining morphological and molecular data (Ni-Ni-Win et al. 2008, 2010, 2011a,b). These studies resulted in the description of eight new species from the western Pacific Ocean (Ni-Ni-Win et al. 2010, 2011a), thereby increasing the recognized regional diversity by no less than $70 \%$. These findings raise two important questions with respect to global diversity and the geographic distributions of the individual species. First, is the spectacular increase in diversity unique to the western Pacific Ocean or will studies of other regions disclose similar patterns? Second, how are the individual species geographically distributed?

A survey of published records of Padina, using AlgaeBase as a source (Guiry and Guiry 2012), suggests that most species are widely distributed (Fig. 1; Table S1 in the Supporting Information). When grouped by marine realm (Spalding et al. 2007), 10
Fig. 1. Species-level diversity and biogeography of Padina based on literature reports. (A) Global map with indication of marine realms following Spalding et al. (2007); (B and C) Richness, percentage of endemism (i.e., species only found in a single realm) and species shared across ocean basin, based on the data provided in supplementary Table S1.

A

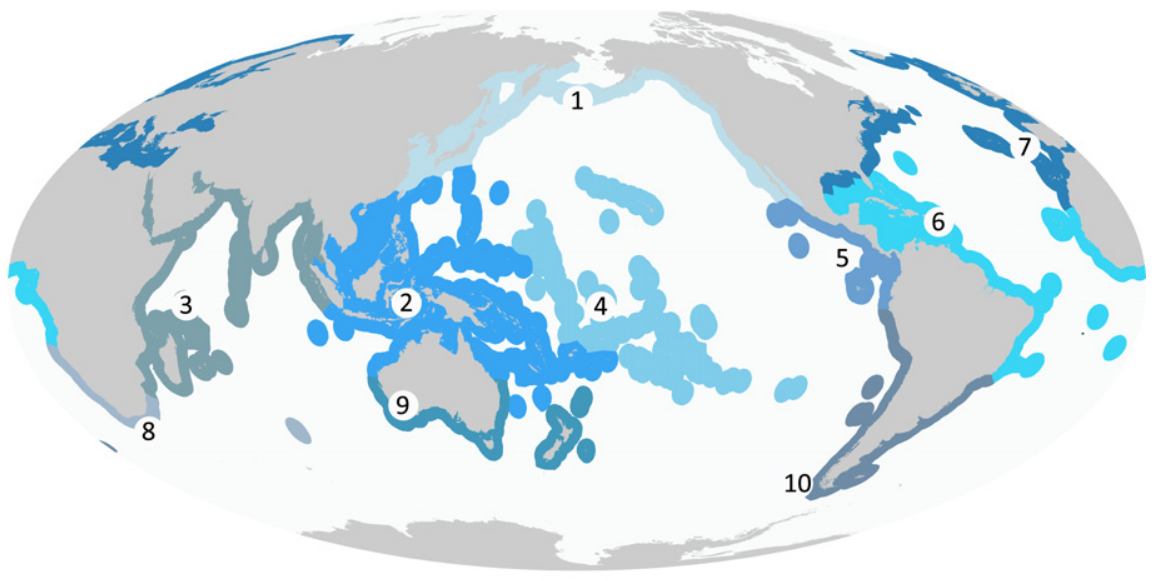

B

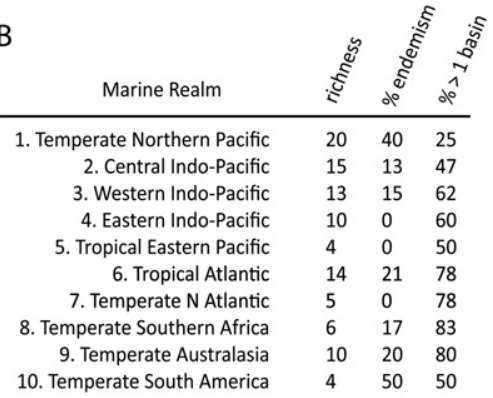

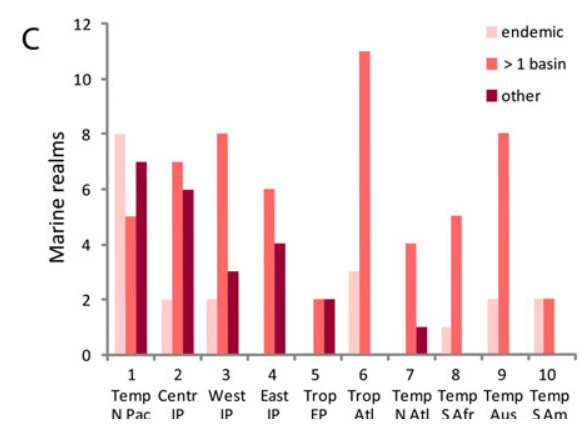


out of 42 currently recognized species have been reported from more than three realms and at least $25 \%$ of the species in each region has been reported outside of its respective ocean basin (e.g., Atlantic species being reported from the Pacific Ocean and vice versa). Consequently, endemism appears to be low for each marine realm. The Temperate Northern Pacific region forms an exception to this trend with $40 \%$ of the species being endemic. The latter region also shares the lowest number of species with other oceans. The presumed endemism in the Temperate Northern Pacific could however also be a direct consequence of the recent taxonomic activity in the region. In general, the older the species name, the wider its distribution (Table S1). It is therefore possible that several of the newly described species have a much broader geographic range than indicated by their present distribution. Alternatively, the presumed large biogeographic ranges of many of the well-established species may simply be an artifact resulting from an inadequate morphology-based classification and repeated misidentifications.

DNA-based sequence delimitation increasingly becomes the method of choice to identify (Hebert et al. 2003) and delimit species (Wiens 2007). Numerous methods have been developed to detect discontinuities in sequence variation associated with species boundaries (e.g., Templeton et al. 1992, Sites and Marshall 2004, Pons et al. 2006), but none of them is without pitfalls. However, by shedding light on the spatial scale at which populations diverge, these methods provide useful initial hypotheses about the number and extent of species-level groupings (Papadopoulou et al. 2009). Furthermore, because algorithmic species delineation does not require priori-defined entities, it is particularly useful in taxa for which morphological identification is problematic, including algae (e.g., Leliaert et al. 2009, Tronholm et al. 2012).

In this study, we aimed to reassess global species diversity, phylogenetic relationships and geographic distribution patterns in Padina, using DNA-sequences as primary data. Species boundaries were tested based on two unlinked loci, using two different algorithmic species delineation approaches. Phylogenetic reconstruction was based on a multigene data set and relied on a significant sampling effort, including numerous collections from previously underrepresented areas. Divergence times were estimated using a relaxed molecular clock approach. The diversity and biogeographic patterns were re-examined as a function of species delimitation, and the biological and taxonomic relevance of increasingly narrow species-level groupings are discussed.

\section{MATERIALS AND METHODS}

Taxon sampling. Taxon sampling consisted of 221 Padina specimens, including 135 specimens for which sequence data were generated in this study. A particular effort was made to include specimens from hitherto underrepresented regions (Australia, the Caribbean Sea, Eastern Pacific, New Caledonia, and Southern Pacific archipelagos). If voucher specimens were available we examined the following morphological characters: the presence of a stipe, the presence of a creeping Vaughaniella-stage, the degree of calcification on both surfaces, the distribution of hair lines and sporangia on both surfaces of the thallus, the position of the tetrasporangial sori relative to the hairlines, the presence of an indusium covering the tetrasporangial sori, and the number of cell layers in the proximal, medial, and distal parts of the thallus. Using this information, specimens were identified using local floras and recent taxonomic treatises. When a Genbank sequence matched with unnamed morphospecies in a well delimited ESU (see below), we provisionally attributed the Genbank name to the whole ESU. Taxonomic information, collection details and morphological information are provided in Table S2 in the Supporting Information. The geographic origin of the samples is indicated on the phylogeny (Figs. 2A and B).

DNA extraction, amplification and sequencing. Total genomic DNA was extracted from tissue samples dried in silica gel using an extraction protocol detailed by Snirc et al. (2010). Three organellar protein-coding regions were PCR-amplified. Sequences of the plastid-encoded $r b c \mathrm{~L}(1,205 \mathrm{nt})$ and $p s a \mathrm{~A}$ $(1,400 \mathrm{nt})$ were amplified and sequenced as two overlapping fragments with the following primer pairs: $r b c \mathrm{~L}-68 \mathrm{~F} / r b c \mathrm{~L}$ $708 \mathrm{R}$ and $r b c \mathrm{~L}-543 \mathrm{~F} / r b c \mathrm{~L}-1381 \mathrm{R}$ for $r b c \mathrm{~L}$ sequences, and $p s a \mathrm{~A}-130 \mathrm{~F} / p s a \mathrm{~A}-940 \mathrm{R}$ and $p s a \mathrm{~A}-870 \mathrm{~F} / p s a \mathrm{~A}-1760 \mathrm{R}$ for $p s a \mathrm{~A}$ sequences. Sequences of the mitochondrial-encoded cox3 (693 nt) were amplified and sequenced as a single PCR product using the primer pair cox3-44F/cox3-739R. Primer sequences, annealing temperatures, and bibliographic sources are provided in Table S3 in the Supporting Information. The PCR mix was prepared following Snirc et al. (2010), for a final reaction volume of $25 \mu \mathrm{L}$. PCR reactions consisted of an initial denaturation step at $94^{\circ} \mathrm{C}$ for $3 \mathrm{~min}$, 35 cycles consisting of a denaturation step at $94^{\circ} \mathrm{C}$ for $45 \mathrm{~s}$, an annealing step for $60 \mathrm{~s}$ at the temperatures given in Table S3, and an elongation step at $72^{\circ} \mathrm{C}$ for $60-90 \mathrm{~s}$, depending on the length of the amplified fragment. The 35 cycles were followed by a final extension step at $72^{\circ} \mathrm{C}$ for 5 min. Purification and cycle sequencing of the resulting PCR products were undertaken by Genoscope (Évry, France), with the same primers as used for the PCR reactions. Electrophoregrams were visually checked, edited and assembled using Sequencher ${ }^{\mathrm{TM}} 4.1$ (Gene Codes Corporation, Ann Arbor, MI, USA). The 334 newly generated sequences were complemented with 145 sequences downloaded from Genbank and aligned manually using MEGA v. 5.0 (Tamura et al. 2011). The dimensions of the resulting alignments were as follows: cox3: 166 sequences, $690 \mathrm{nt}$; psaA: 134 sequences, 1,569 nt; rbcL: 193 sequences, 1,088 nt. Genbank accession numbers are provided in Table S2.

Sequence-based species delineation. Individual gene trees, constructed using the neighbor-joining algorithm in MEGA v. 5.0 (Tamura et al. 2011) and subjected to 1,000 bootstrap replicates, were visually compared for the presence of concordant terminal clades. Next, we explored two single-locus species delimitation methods using both the $\operatorname{cox} 3$ and $r b c \mathrm{~L}$ data sets to assess species boundaries within the genus. The psaA data set was not submitted to separate analysis because the amount of missing data was too high, when compared to the $r b c \mathrm{~L}$ and cox3 data sets ( $c a 42 \%$ of missing data for psaA, $15 \%$ for $r b c \mathrm{~L}$ and $28 \%$ for cox3). For most of the Genbank-retrieved taxa psaA sequences were also not available.

We used a GMYC model developed by Pons et al. (2006). The method has been used to delimit species boundaries in a 
A

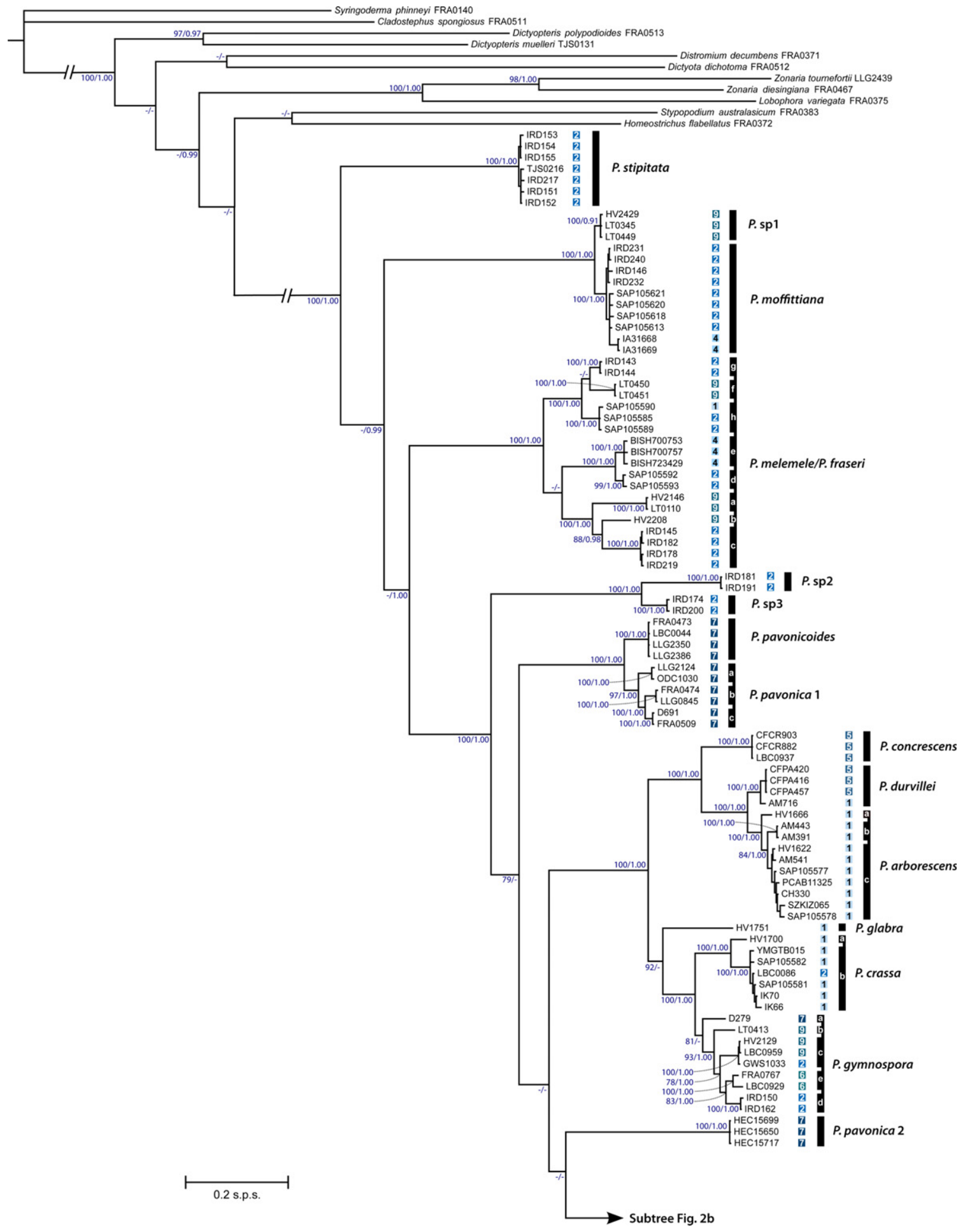

Fig. 2. (A) First part ("root") of the phylogram resulting from the Bayesian analysis of the combined 3-gene data set (211 taxa, 3,347 nt). Nodes are labelled with statistical support values. The first value is the percentage of bootstrap in ML analysis; the second value is the posterior probability of the corresponding node in Bayesian inference. Only values above $75 \%$ for ML bootstrap (BP) and above 0.95 for PP are shown. Below these threshold values, the support values are indicated by a dash; support values were not indicated for intra-ESUs nodes and nodes for which BP and PP values were both below their respective thresholds. Numbers in boxes in different shades of blue refer to marine realms as defined in Figure 1. Letters in vertical black bars refer to the cox3 GMYC clusters, as displayed in Figure 3. (B) Second part ("crown") of the phylogram resulting from the Bayesian analysis of the combined 3-gene data set (211 taxa, 3,347 nt). See caption of Figure 2A for explanations. 
B

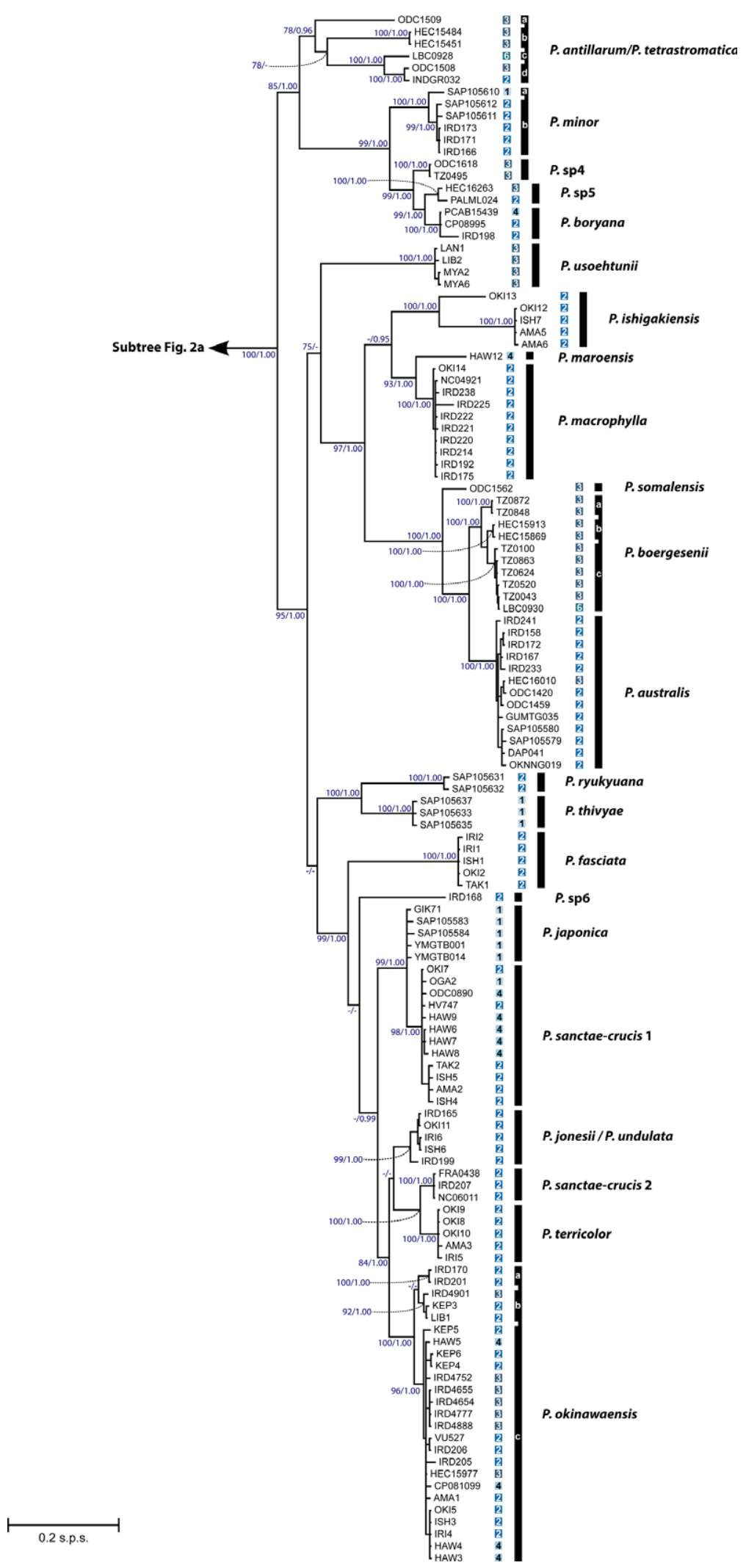

FIG. 2. Continued 
variety of taxonomically problematic taxa (see Fontaneto et al. 2007, 2009, Jousselin et al. 2009, Leliaert et al. 2009, Pinzón-Navarro et al. 2010, Tronholm et al. 2012). In a ML framework, the algorithm optimizes the shift in the branching patterns from interspecific branches (Yule model) to intraspecific branches (coalescent model) using an ultrametric tree. A threshold value is calculated such that nodes older than this threshold can be regarded as species diversification events, while younger nodes are identified as coalescencedriven clusters. An ultrametric tree using unique haplotypes only was constructed in BEAST v1.6.2 (Drummond and Rambaut 2007) under a GTR + I + G model with an uncorrelated lognormal (UCLN) relaxed molecular clock model (Drummond et al. 2006) and coalescent tree prior. A Markov Chain Monte Carlo analysis was run for 10 million generations, with sampling every 1,000 generations. The output was diagnosed for convergence using Tracer v.1.5 (Rambaut \& Drummond 2009), and summary statistics and trees were generated using the last five million generations with TreeAnnotator v1.6.2 (Rambaut \& Drummond 2011). GMYC analyses were performed under a single-threshold model (Monaghan et al. 2009) using the SPLITS package in $R$ ( $R$ Development Core Team 2009; package available at http://r-forge.r-project.org/ projects/splits/).

Patterns of sequence variation were also investigated for the presence of species-level groups by identifying independent networks using statistical parsimony (Templeton et al. 1992, Sites and Marshall 2003). The network analysis partitions the data into independent networks of haplotypes connected by changes that are non-homoplastic with a $95 \%$ probability (Templeton et al. 1992). Statistical parsimony networks of the $r b c \mathrm{~L}$ and $\operatorname{cox} 3$ alignments were constructed with TCS 1.21 (Clement et al. 2000), with calculated maximum connection steps set at $95 \%$. To eliminate missing data at $5^{\prime}$ and $3^{\prime}$ ends of the alignment, the $\operatorname{cox} 3$ data set was pruned down to 588 nucleotides. For the $r b c \mathrm{~L}$ data set we removed six highly incomplete sequences $(\sim 50 \%$ missing characters $)$, rather than to prune the entire alignment.

Clades were recognized as putative species (further referred to as, ESUs) if they satisfied the following criteria: (i) the clades were compatible with the statistical parsimony or the GMYC ML solution as species in the $\operatorname{cox} 3$ or $r b c \mathrm{~L}$ analyses; and (ii) the clades were well supported or were at least not contradicted with high nodal support in the individual gene trees (genealogical concordance according to Dettman et al. (2003)).

Phylogenetic reconstruction. The three individual alignments were concatenated, yielding a 3,347 nt alignment. Only sequences obtained from the same voucher specimen were concatenated, resulting in a matrix which was $71 \%$ filled at the gene level. Eleven members of the Sphacelariales-Syringodermatales-Dictyotales clade (see Bittner et al. 2008) were selected as outgroup. All analyses on the concatenated threelocus alignment were carried out with a model in which the data set was partitioned by gene and by codon position, thus defining nine partitions. The best model parameters fitting the separate $r b c \mathrm{~L}, p s a \mathrm{~A}$ and $c o x 3$ alignments were determined using JModelTest v3.0.6 (Posada 2008), which recovered a GTR + I + G model. ML phylogenies were inferred using RAxML (Stamatakis 2006, Stamatakis et al. 2008) with GTR + I + G model parameters estimated independently for each partition as described above. Statistical support was assessed by performing 1,000 rapid bootstrap replicates as implemented on the RAxML BlackBox server (Stamatakis et al. 2008). The three-gene data set was also subjected to Bayesian phylogenetic analyses, carried out using MrBayes v3.1.2 (Huelsenbeck and Ronquist 2001, Ronquist and Huelsenbeck 2003) with the same partitioning strategy. Analyses consisted of two independent runs with four incrementally heated Metropolis-coupled Monte-Carlo Markov Chains each. Each chain was run for 5 million generations with trees and data sampled every 1,000 generations. Convergence of loglikelihoods and parameter values was assessed in Tracer v1 (Rambaut and Drummond 2009). Nodal support was assessed by calculating PP values of each node of the resulting consensus tree.

Inference of divergence times. The timing of divergence between lineages was tentatively inferred by means of a chronogram based on the multigene alignment but including only a single concatenated sequence for each ESU. The resulting matrix contained 74 taxa (63 Padina lineages and 11 outgroup taxa) and was $91 \%$ filled at the gene level (Table S4 in the Supporting Information). Two nodes in the tree were constrained in geological time based on a previously published brown algal time-calibrated phylogeny (Silberfeld et al. 2010). The split between the Dictyotales and the outgroup was constrained between 130 and 195 Ma using a uniform prior. The age of Padina was constrained at $95 \mathrm{Ma}$ and tailing off according to a gamma distribution with shape $=3.0$ and scale $=5.5$ to reflect uncertainty about the node age. Time-calibrated trees were constructed in BEAST v1.6.2 (Drummond and Rambaut 2007) under a GTR + I + G model with an UCLN relaxed molecular clock model (Drummond et al. 2006) and Yule tree prior. We applied the same partition strategy for the concatenated data set. Clock models and trees were linked across partitions. Four independent Markov Chain Monte Carlo analyses were run for 10 million generations, sampling every 1,000 generations. The output was diagnosed for convergence using Tracer $\mathrm{v}$ 1.5, and summary statistics and trees were generated using the combined last 5 million generations of each run with LogCombiner v1.6.2 and TreeAnnotator v1.6.2 (Rambaut \& Drummond 2011). We used GenGIS v.1.08 (Parks et al. 2009) to visualize the geographic imprint of the phylogenetic relationships within the $P$. melemele/ $P$. fraseri clade.

\section{RESULTS}

Species delineation. The cox3 and $r b c \mathrm{~L}$ alignments were subjected to algorithmic species delineation using GMYC- and statistical parsimony-based methods. Results of the species delimitation are summarized in Table 1 and Figures $3, \mathrm{~S} 1$ and $\mathrm{S} 2$ in the Supporting Information. For the cox3 data, the GMYC model provided a significantly better fit than null model driven by coalescence only $\left(\ln \mathrm{L}_{\mathrm{GMYC}}=\right.$ $\left.686.83>\ln \mathrm{L}_{0}=681.01, \quad P=0.008\right)$. Although a GMYC model was also favored over a pure coalescence model for the $r b c \mathrm{~L}$ data, the difference was not significant $\left(\ln \mathrm{L}_{\mathrm{GMYC}}=672.54>\ln \mathrm{L}_{0}=669.77\right.$, $P=0.135)$. For the cox3 tree the GMYC model

TABLE 1. Lineage branching pattern fit to a single-threshold GMYC model for $c o x 3$ and $r b c \mathrm{~L}$ data sets.

\begin{tabular}{lrcccccr}
\hline \hline Gene & \multicolumn{1}{c}{$H$} & $T$ & $\mathrm{~L}_{0}$ & $\mathrm{~L}_{\mathrm{GMYC}}$ & $P$ & $N_{\mathrm{GMYC}}$ & \multicolumn{1}{c}{$\mathrm{CI}$} \\
\hline $\operatorname{cox3}$ & 100 & -0.0041 & 681.01 & 686.83 & 0.008 & 61 & $10-74$ \\
$r b c \mathrm{~L}$ & 97 & -0.0044 & 669.77 & 672.54 & 0.135 & 56 & $2-63$
\end{tabular}

$\mathrm{H}$ : number of unique haplotypes; $\mathrm{T}$ : relative threshold time; $\mathrm{L}_{0}$ : Log likelihood of the null model, a pure coalescent tree; $\mathrm{L}_{\mathrm{GMYC}}$ : Log likelihood of the general mixed Yule coalescent model; $P$ : $P$-value of a likelihood ratio test; $N_{\mathrm{GMYC}}$ : number of GMYC lineages; CI: confidence interval. 


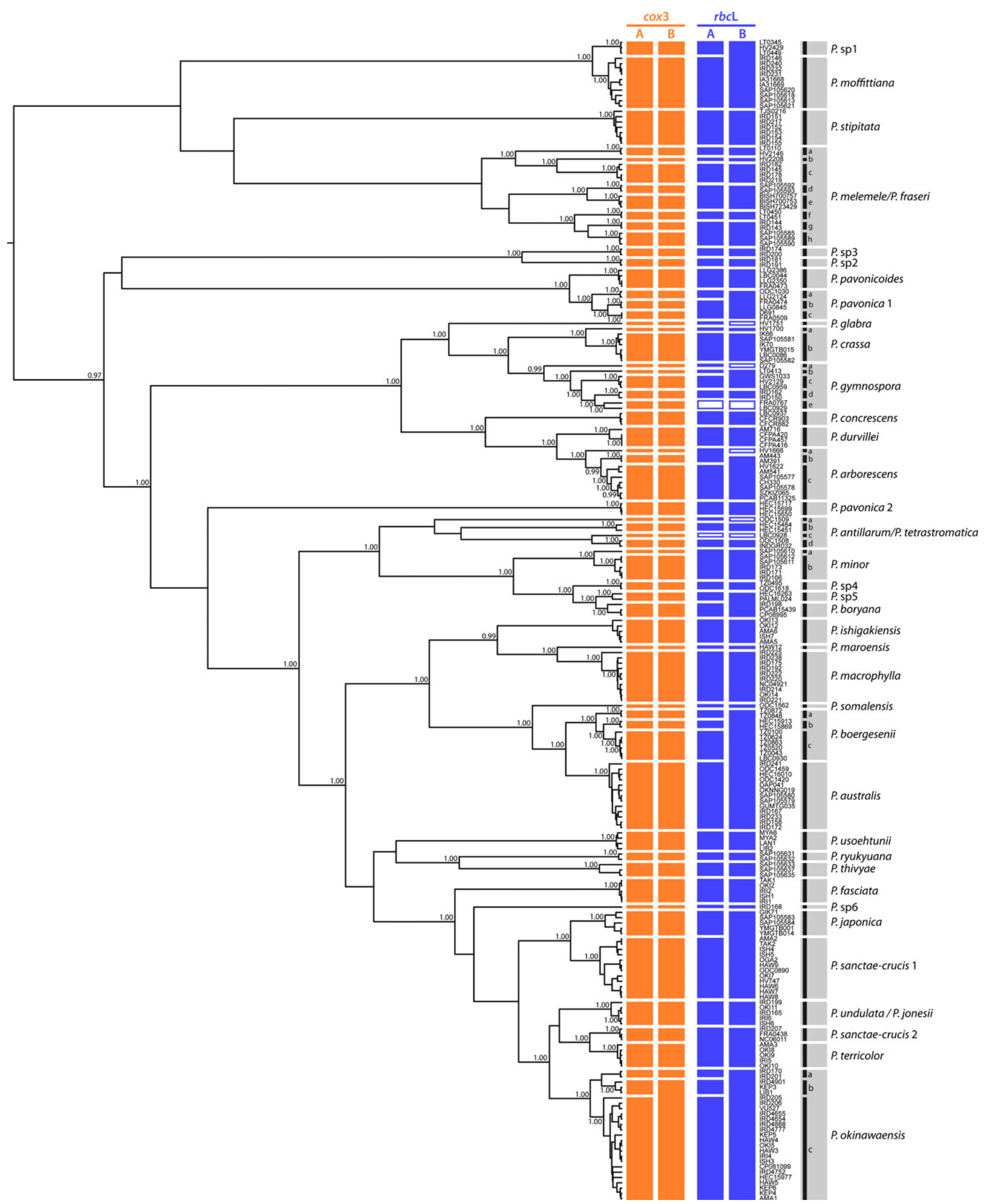

FIG. 3. Ultrametric tree constructed using a coalescent tree prior in BEAST with results from GMYC- and parsimony-based algorithmic species delimitation methods. The columns to the right of the tree indicate separately evolving lineages obtained under GMYC (column A) and statistical parsimony methods (column B) for the $c o x 3$ (in orange) and $r b c \mathrm{~L}$ (in purple) genes, respectively. The last column indicates the cox3 GMYC clusters with black bars and letters, for each ESU. Open boxes denote missing data. 


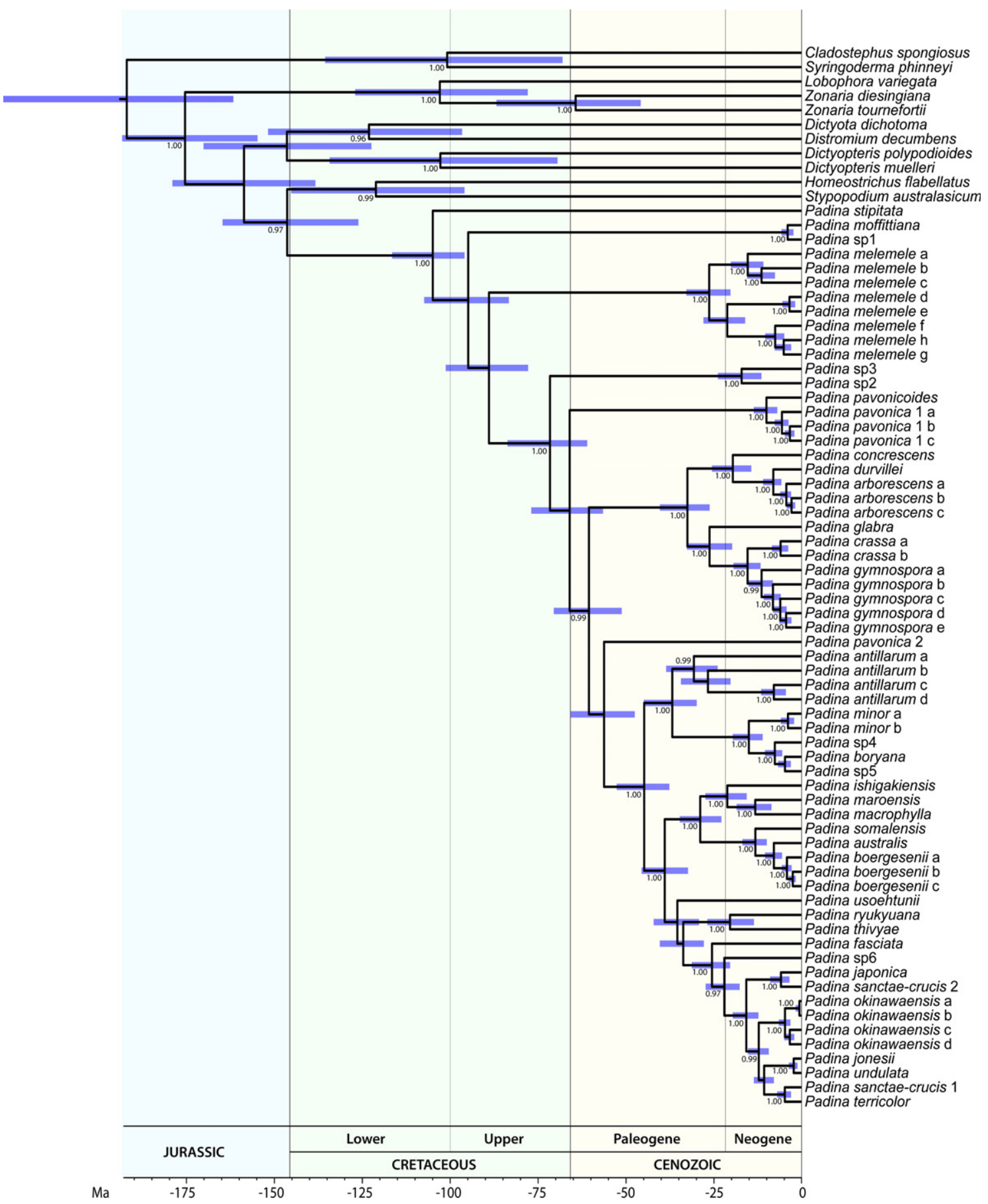

FIG. 4. Chronogram constructed under a Bayesian relaxed clock model using BEAST, on the basis of a data set retaining only one specimen per cluster, as shown in Figure 2. The analysis was carried out with four independent runs of 10,000,000 generations each, sampled every 1,000 th tree, under a Yule model.

recovered 61 clusters, while for the $r b c \mathrm{~L}$ tree 56 clusters were recognized. The confidence interval was very large, [10-74] and [2-63] for the $\operatorname{cox} 3$ and $r b c \mathrm{~L}$ trees respectively. Species delimitation based on the $r b c \mathrm{~L}$ data set appeared slightly more conservative than on the cox3 alignment. Several cox3 GMYC lineages were recognized as a single cluster in the $r b c \mathrm{~L}$ analysis (e.g., Padina melemele d-e, P. melemele 7-8,
P. minor a-b, P. pavonica c-d, P. sanctae-crucis 2-P. terricolor, $P$. arborescens $\mathrm{a}-\mathrm{b})$. Results of the statistical parsimony analyses were highly congruent with the GMYC modelling. For the cox3 data set, results were nearly identical. Differences are somewhat more outspoken for the $r b c \mathrm{~L}$ alignment whereby several GMYC lineages did not segregate into independent networks (e.g., P. boergesenii-P. australis, P. japonica-P. sanctae- 


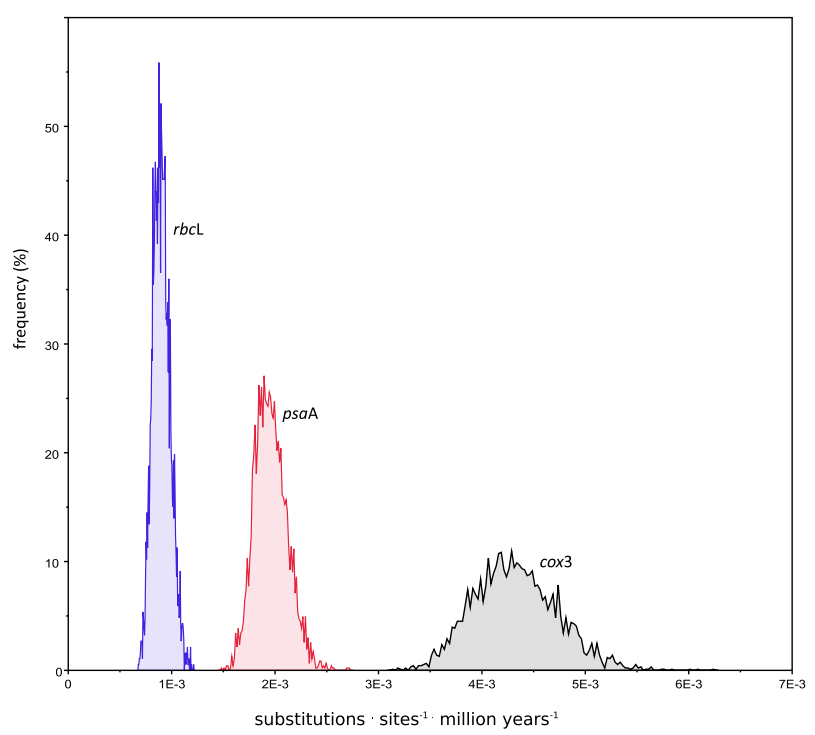

FIG. 5. Mean substitution rate (substitutions/site Myr) for the $r b c \mathrm{~L}$ (blue), psaA (red), and cox3 (gray) genes, derived from a species-level Bayesian analysis with gene-specific molecular clock rates.

crucis 1, P.moffitiana-sp1, P. pavonica (c-d)-b, P. arborescens $-P$. durvillei). The cox3-delineated clusters generally corresponded to well-supported clades in the two individual gene trees, or at least were not contradicted with high support, resulting in the recognition of 61 ESUs.

Three-gene phylogeny. Basic statistics for the separate alignments, as well as estimates of model parameters with JModeltest, are presented in Table S5 in the Supporting Information. The combined data set consisted of 3,347 nucleotides (nt) and included 1,937 constant sites (CS) and 1213 parsimony-informative sites (PI). The ML and Bayesian phylogenies were highly similar. The results are presented using the Bayesian topology with support values from both analyses indicated at each node. To improve readability the phylogram was split in two parts, displayed on Figure 2A ("root" part) and Figure 2B ("crown" part), respectively. Our 3-gene analyses result in a well-resolved phylogeny, with moderate to strong support for most of the backbone nodes. The monophyly of Padina was fully supported.

The morphological assignment of the specimens included in our data set is generally consistent with the phylogenetic structure of the tree: most ESUs gather all specimens that were preliminary assigned to a given morphospecies, as detailed in Table S2. Six ESUs could not be assigned to any existing morphospecies, hereafter referred to as Padina sp.1-6. Three morphospecies are not recovered as single clades: (i) Specimens of the Atlantic-Mediterranean $P$. pavonica are split into four ESUs in two unrelated clades, hereafter referred to as " $P$. pavonica 1 " and “P. pavonica 2". Padina pavonica 1 encompasses 3 ESUs from various localities on Mediterranean and Atlantic coasts, whereas $P$. pavonica 2 includes specimens that were collected off the Madeira Archipelago. (ii) Specimens of $P$. sanctae-crucis are also split into two non-sister ESUs, referred to as " $P$. sanctaecrucis 1 " and "P. sanctae-crucis 2." P. sanctae-crucis 1 clusters specimens collected in New Caledonia, and is sister to the recently described $P$. terricolor from Japan. $P$. sanctae-crucis 2 includes specimens from Hawaii and tropical Japan, and is sister to P. japonica. (iii) The three Japanese specimens (OKI11, IRI6, ISH6) of the recently described $P$. undulata are merged in a single ESU with two specimens from New Caledonia that were identified as $P$. jonesii (IRD165, IRD199). This inconsistency requires additional investigations, preferably including topotype collections of $P$. jonesii from Guam, to establish the identity of the taxon unequivocally.

Time-calibrated phylogeny. The consensus chronogram resulting from the BEAST analysis is presented in Figure 4. As a consequence of the small number of calibration points, the 95\% HPD increase substantially toward the root of the tree. Nonetheless, a comparison of mean ages between nodes provides a time frame for the evolution of Padina. According to the chronogram, the genus Padina originated in the Lower Cretaceous. Extant lineages diverged regularly from the Upper Cretaceous upwards. No clear variation in the tempo of divergences could be

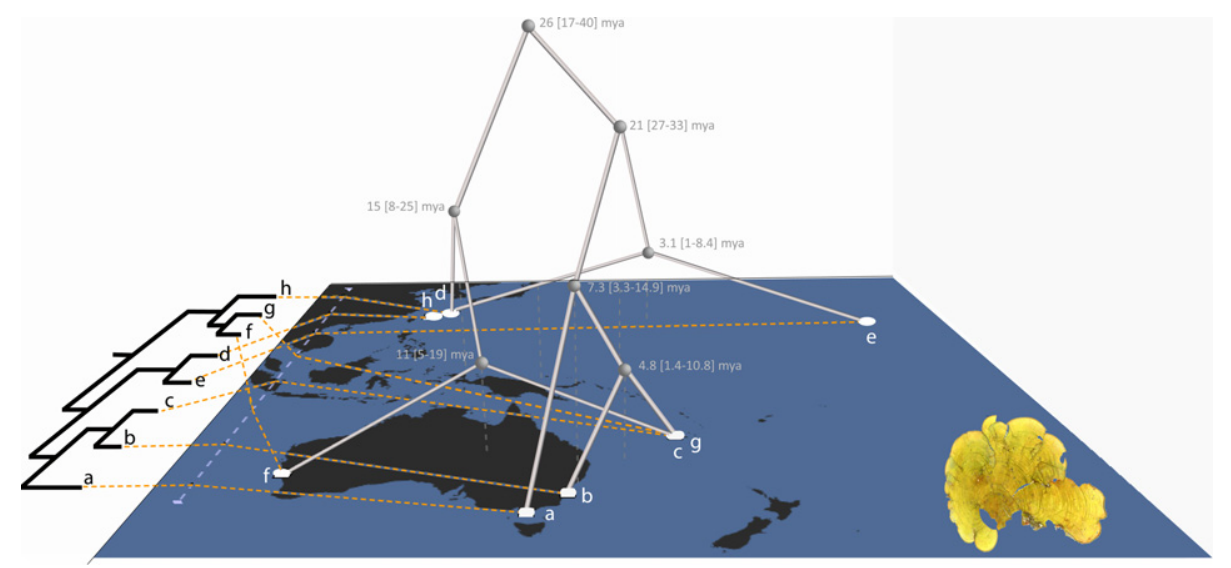

FIG. 6. Diversification of the Padina melemele/ $P$. fraseri clade in the Indo-Pacific Ocean. 
observed in the backbone of the tree. Conversely, a few lineages (e.g., P. melemele, $P$. pavonica 1 ) display a pattern with a late diversification episode occurring after a long period of time with no apparent divergences: ca $60 \mathrm{Ma}$ for $P$. melemele and ca $50 \mathrm{Ma}$ for P. pavonica.

\section{DISCUSSION}

Species delineation and diversity. We assessed species-level diversity of Padina using two algorithmic species delineation techniques based on two unlinked loci ( $c o x 3$ and $r b c \mathrm{~L}$ ). Our analyses demonstrated the utility of DNA-based species delimitation although displaying variation between analyses and loci. The variation among the four analyses was largely gene-dependent. Differences between GMYC and statistical parsimony were less outspoken, but when present, clusters were usually merged under the statistical parsimony criterion while recovered as separate entities in the GMYC analysis. The GMYC procedure yielded more conservative estimates for the $r b c \mathrm{~L}$ data (56 lineages) than for cox3 (61 lineages). Differences among species delimitation approaches (GMYC, statistical parsimony, reciprocal monophyly) are predominantly found between sister lineages that have diverged relatively recently $(<4 \mathrm{Ma})$. An explanation is offered by the variation in substitution rate between both genes. The mean substitution rate of the $r b c \mathrm{~L}$ gene was estimated to be $9.2 \times 10^{-4}$ substitutions per site per Ma, which is nearly 5-fold slower than the mean substitution rate estimated for the cox3 gene $\left(4.3 \times 10^{-3}\right.$ substitutions per site per Ma; Fig. 5). This explains why speciation events more recent than $\sim 4 \mathrm{Ma}$ (translating in p-distances $<1 \%$ ) are not well captured by the $r b c \mathrm{~L}$ gene. For the same time period, cox3 divergence would amount to more than $3 \%$. The most recent divergence resolved using the cox3 gene data was as recent as 500,000 years ( $P$. okinawaensis "a" and "b").

Although presenting an objective tool to define species boundaries, DNA-based, algorithmic species delineation techniques have been criticized because they may overestimate species numbers (e.g., Lohse 2009, Papadopoulou et al. 2009). It is therefore appropriate to discuss the biological relevance of the ESUs delineated in this study. Lohse (2009) pointed out that GMYC models have a tendency to overestimate species numbers when sampling of intraspecific variation is low or uneven. Although we have sampled Padina across most of its biogeographic range, intraspecific variation is likely to be undersampled for some species. This makes it difficult to discern cases of genetic differentiation and population divergence from artifacts caused by incomplete taxon sampling. A good illustration is presented by $P$. okinawaensis, which segregates in three of four delineation analyses into three ESUs. It is indeed possible that undersampling of genetic variation may have caused the outcome of the analyses. How- ever, our analyses provide evidence for genetic cohesion across large spatial scales, as demonstrated by $P$. okinawaensis " $\mathrm{c}$ " which was collected in the entire Indo-West Pacific, spanning on 3 marine realms. In addition, it is evident that the genetic variation within $P$. okinawaensis-clade is not strictly geographically defined. At least one specimen from the Maldives (IRD4901) clusters with specimens from Indonesia and Thailand rather than with the other Maldive specimens, which are recovered in P. okinawaensis c. These results demonstrate that artifacts due to incomplete taxon sampling will most likely not alter the overall diversity estimates. Additional justification of the biological relevance of the ESUs recovered by our species delineation is presented by the recent description of two Mediterranean species, $P$. pavonicoides and $P$. ditristromatica (Ni-Ni-Win et al. 2011b). Careful morphological examination by $\mathrm{Ni}-\mathrm{Ni}$-Win and coworkers demonstrated distinct morphological characters that set these new species aside from other closely related ESUs of the $P$. pavonica 1 clade. On a similar note, Ni-Ni-Win et al. (2011a) used the name $P$. tetrastromatica Hauck for Indo-Pacific specimens that are characterized by typical $P$. antillarum morphologies, despite the fact that Wynne (1998) treated the Indo-Pacific P. tetrastromatica as a synonym of P.antillarum, originally described from the Caribbean Sea. Our species delineation confirms the suspicion of $\mathrm{Ni}-\mathrm{Ni}$-Win et al. (2011a) and supports the distinction between separate evolving Atlantic and Indo-Pacific lineages.

Biogeography and diversification. Literature data suggest that most Padina species have large biogeographic distributions, with a significant fraction of species being reported from more than one ocean basin. On the other hand, many recently described species are presently known only from a rather small geographic area (e.g., the NW Pacific Ocean, Ni-NiWin et al. 2010, 2011a, Mediterranean Sea, Ni-NiWin et al. 2011b). Our global taxon sampling enables us to refine our ideas on species ranges. The ESUs delineated in this study are in all but one case confined to either the Atlantic or to the Indo-Pacific Ocean. The only exception to this is presented by a single specimen identified as P. boergesenii (LBC0930) from Costa Rica, which resolves in an East African ESU. In all other cases, the distinction between Atlantic and Indo-Pacific ESUs is absolute. Also at the marine realm level, species that are confined to a single realm dominate. Eighty percent of the ESUs are confined to a single realm and $16 \%$ are found in two, usually neighboring realms (Table $\mathrm{S} 6$ in the Supporting Information). Only two ESUs, $P$. okinawaensis $\mathrm{C}$ and $P$. sanctaecrucis 1 are found in three realms. The Western, Central, and Eastern Indo-Pacific realms appear to be least differentiated relative to one another. Most of often ESUs that cover more than a single realm are distributed in these areas.

As a rule, globally distributed morphospecies segregate into ESUs with more restricted ranges. For 
example, $P$. antillarum and $P$. gymnospora, which appear to be widely distributed in tropical to warm temperate seas, consist of numerous ESUs that are confined to the Atlantic or Indo-Pacific. This indicates that the current North-South orientation of the continents may act as an effective dispersal barrier in the genus Padina. The Caribbean P. antillarum "b" diverged from its Indo-Pacific sister clade (P. antillarum "c" \& "d") circa $30 \mathrm{Ma}$, which significantly predates the final closure of the Tethyan seaway near the Levant (12-19 Ma; Steininger and Rögl 1984). Similar estimates have been made for Halimeda and Dictyota (Verbruggen et al. 2009, Tronholm et al. 2012). This supports the idea that the collision of the African and European plates in the Miocene reinforced rather than caused vicariant events leading to divergence of Indo-Pacific and Atlantic lineages. The most recent divergence between the Indo-Pacific and Atlantic sister lineages of $P$. gymnospora ("d" and "e") is considerably younger, ca. 5 Ma. At that time in early Pliocene, the Central American isthmus had not formed yet, leaving an open connection between the western Atlantic and the Pacific Ocean. More comprehensive sampling, however, is potentially needed to be more conclusive about the most likely connections.

Within ocean basins two patterns stand out. First, some species are characterized by ranges spanning two to four marine realms. Good examples are presented by $P$. australis, $P$. macrophylla and $P$. moffittiana whose ranges span the Western, Central, and Eastern Indo-Pacific. This indicates that at least some of the species recently described from the western Pacific Ocean are much more widespread, and that gene flow across vast geographic distances is sufficient to maintain cohesive entities. Second, many morphospecies segregate into separate ESUs, which themselves are range-restricted (e.g., P. melemele) or not (e.g., $P$. okinawaensis "c"). An example of the former is presented by the $P$. melemele/ $P$. fraseri clade, which gradually diverged in the Indo-Pacific since the late Oligocene, with separate lineages nearly exclusively confined to Australia, Japan, Hawaii or New Caledonia (Fig. 6). Genetic distances, however, do not necessarily reflect geographic closeness. The two Japanese lineages ("d" and "h") are for example closer relatives to the Hawaiian and Australian/New Caledonian lineages, respectively, than to each other. Such patterns can easily arise by founder events and subsequent peripatric speciation, hypothesized to dominate speciation mechanisms for coastal marine organisms in the Indo-Pacific (Paulay and Meyer 2002, Malay and Paulay 2009). A second interesting case is presented by the $P$. arborescens and $P$. crassa clades, distributed across the temperate northern Pacific Ocean. $P$. crassa segregates in two ESUs, from eastern (Mexico) and western Pacific (Japan, Korea, and China), respectively. P. arborescens on the other hand segregates in three ESUs, two confined to the Gulf of California, Mexico and one containing Japanese as well as Mexican samples. The mixed clade as well as divergence times between these warm temperate lineages younger than $5 \mathrm{Ma}$ indicate that gene flow across the world's most potent marine biogeographic barrier has not completely halted since Cenozoic global cooling. A more comprehensive sampling of the northern Pacific taxa, as well as refined molecular dating estimates, could shed light on the tempo of the episodes of dispersal.

In conclusion, we demonstrate that a biogeography based on literature reports and traditional names is highly inaccurate for the genus Padina. Biogeographic ranges that presumably spanned several ocean basins are artifacts due to inaccurate identification. DNA-based species delineation results in ESUs whose ranges are predominantly restricted to a single marine realm (Supplementary Table S6). Future sampling may expand the ranges of several of the species that are presently only known from a single realm, especially in the IndoPacific Ocean. However, the restricted range of many species also indicates that additional diversity in the genus Padina is likely to be unveiled with increased sampling.

We are most grateful to our colleagues for collecting specimens (see Table S2). The molecular work was undertaken at the "Service de Systématique Moléculaire" of the Muséum National d'Histoire Naturelle (UMS 2700); we are grateful to the late Annie Tillier, Céline Bonillo and Josie Lambourdière for their help and advice in the molecular lab. Bayesian analyses were carried out using the Stevin Supercomputer Infrastructure at Ghent University, funded by Ghent University, the Hercules Foundation and the Flemish Government department EWI. This work was supported by the "Consortium National de Recherche en Génomique" and the "Action Transversale du Muséum" (ATM) "Barcode." It is part of the agreement no. 2005/67 between the Genoscope and the Muséum National d'Histoire Naturelle on the project "Macrophylogeny of life" directed by Prof. Guillaume Lecointre. Thomas Silberfeld benefited of a grant from the French "Ministère de l'enseignement supérieur et de la recherche." Olivier De Clerck is indebted to Lennert Tyberghein for assistance with GenGis and to the Research Foundation-Flanders (FWO) for research grant G.0142.05.

Abbott, I. A. \& Huisman, J. M. 2003. New species, observations, and a list of new records of brown algae (Phaeophyceae) from the Hawaiian Islands. Phycol. Res. 51:173-85.

Ávila-Ortiz, A. G. \& Pedroche, F. F. 1999. Padina tetrastromatica Hauck, a misapplied name for $P$. crispata Thivy in Pacific Mexico. Bot. Mar. 42:355-8.

Ávila-Ortiz, A. \& Pedroche, F. F. 2005. El género Padina (Dictyotaceae, Phaeophyceae) en la región tropical del Pacífico mexicano. Monografías Ficológicas 2:139-71.

Bittner, L., Payri, C. E., Couloux, A., Cruaud, C., de Reviers, B. \& Rousseau, F. 2008. Molecular phylogeny of the Dictyotales and their position within the Phaeophyceae, based on nuclear, plastid and mitochondrial DNA sequence data. Mol. Phylogenet. Evol. 49:211-26.

Borowitzka, M. A. 1982. Morphological and cytological aspects of algal calcification. Int. Rev. Cytol. 74:127-62.

Clement, M., Posada, D. \& Krandall, K. A. 2000. TCS: a computer program to estimate gene genealogies. Mol. Ecol. 9:1657-9. 
Cribb, A. B. 1951. Invalidation of the genus Vaughaniella. Nature 168:302.

Dettman, J. R., Jacobson, D. J. \& Taylor, J. W. 2003. A multilocus genealogical approach to phylogenetic species recognition in the model eukaryote Neurospora. Evolution 57:2703-20.

Diaz-Pulido, G., Villamil, L. \& Almanza, V. 2007. Herbivory effects on the morphology of the brown alga Padina boergesenii (Phaeophyta). Phycologia 46:131-6.

Drummond, A. J., Ho, S. Y. W., Phillips, M. J. \& Rambaut, A. 2006. Relaxed phylogenetics and dating with confidence. PLoS Biol. 4:e88.

Drummond, A. J. \& Rambaut, A. 2007. BEAST: Bayesian evolutionary analysis by sampling trees. BMC Evol. Biol. 7:214.

Fontaneto, D., Herniou, E. A., Boschetti, C., Caprioli, M., Melone, G., Ricci, C. \& Barraclough, T. G. 2007. Independently evolving species in asexual bdelloid rotifers. PLoS Biol. 5:e87.

Fontaneto, D., Kaya, M., Herniou, E. A. \& Barraclough, T. G. 2009. Extreme levels of hidden diversity in microscopic animals (Rotifera) revealed by DNA taxonomy. Mol. Phylogenet. Evol. 53:182-9.

Gaillard, J. 1975. Padina sanctae-crucis Boergesen, Padina japonica Yamada, Padina haitiensis Thivy et leurs affinités. Le Botaniste 57:85-103.

Geraldino, P. J. L., Liao, L. M. \& Boo, S. M. 2005. Morphological study of the marine algal genus Padina (Dictyotales, Phaeophyceae) from southern Philippines: 3 species new to Philippines. Algae 20:99-112.

Guiry, M. D. \& Guiry, G. M. 2012. AlgaeBase. World-wide electronic publication, National University of Ireland, Galway. Available at: http://www.algaebase.org (accessed 13 January 2012).

Hebert, P. D. N., Cywinska, A., Ball, S. L. \& DeWaard, J. R. 2003. Biological identifications through DNA barcodes. Proc. Roy. Soc. Ser. B 270:313-21.

Huelsenbeck, J. P. \& Ronquist, F. 2001. MrBAYES: Bayesian inference of phylogeny. Bioinformatics 17:754-5.

Jousselin, E., Desdevises, Y. \& d'Acier, A. C. 2009. Fine-scale cospeciation between Brachycaudus and Buchnera aphidicola: bacterial genome helps define species and evolutionary relationships in aphids. Proc. Roy. Soc. Ser. B 276:187-96.

Kraft, G. T., Saunders, G. W., Abbott, I. A. \& Haroun, R. J. 2004 A uniquely calcified brown alga from Hawaii: Newhousia imbricata gen. et sp. nov. (Dictyotales, Phaeophyceae). J. Phycol. 40:383-94.

Lee, Y. P. \& Kamura, S. 1991. Padina ryukyuana Lee, Y.P. et Kamura, a new marine brown alga from southern Japan. Algae $6: 91-6$.

Leliaert, F., Verbruggen, H., Wysor, B. \& De Clerck, O. 2009. DNA taxonomy in morphologically plastic taxa: Algorithmic species delimitation in the Boodlea complex (Chlorophyta: Cladophorales). Mol. Phylogenet. Evol. 53:122-33.

Liddle, L. B. 1975. The effect of intertidal stress on Padina sanctae-crucis (Phaeophyta). J. Phycol. 11:327-30.

Lohse, K. 2009. Can mtDNA be used to delimit species? A response to Pons et al. (2006). Syst. Biol. 58:439-42.

Malay, M. C. M. D. \& Paulay, G. 2009. Peripatric speciation drives diversification and distributional pattern of reef hermit crabs (Decapoda: Diogenidae: Calcinus). Evolution 64:632-64.

Miyata, M., Okazaki, M. \& Furuya, K. 1977. Site and nature of calcium carbonate deposits in a calcareous brown alga Padina japonica (Studies on the calcium carbonate deposition of algae I). Bull. Jpn. Soc. Phycol. 25:1-6.

Monaghan, M. T., Wild, R., Elliot, M., Fujisawa, T., Balke, M., Inward, D. J. G., Lees, D. C., Ranaivosolo, R., Eggleton, P., Barraclough, T. G. \& Vogler, A. P. 2009. Accelerated species inventory on Madagascar using coalescent-based models of species delineation. Syst. Biol. 58:298-311.

Mshigeni, K. E. \& Mkwizu, K. J. K. 1978. Contributions to the embryology of Padina gymnospora (Phaeophyta, Dictyotales). Bot. Mar. 21:331-6.

Ni-Ni-Win, Hanyuda, T., Arai, S., Uchimura, M., Abbott, I. A. \& Kawai, H. 2008. Three new records of Padina in Japan based on morphological and molecular markers. Phycol. Res. 56:288 -300 .
Ni-Ni-Win, Hanyuda, T., Arai, S., Uchimura, M., Prathep, A., Draisma, S. G. A., Phang, S. M., Abbott, I. A., Millar, A. J. K. \& Kawai, H. 2011a. A taxonomic study of the genus Padina (Dictyotales, Phaeophyceae) including the description of four new species from Japan, Hawaii, and the Andaman sea. J. Phycol. 47:1193-209.

Ni-Ni-Win, Hanyuda, T., Arai, S., Uchimura, M., Prathep, A., Draisma, S. G. A., Soe-Htun \& Kawai, H. 2010. Four new species of Padina (Dictyotales, Phaeophyceae) from the western Pacific Ocean, and reinstatement of Padina japonica. Phycologia 49:136-53.

Ni-Ni-Win, Hanyuda, T., Draisma, S. G. A., Furnari, G., Meinesz, A. \& Kawai, H. 2011b. Padina ditristromatica sp. nov. and Padina pavonicoides sp. nov. (Dictyotales, Phaeophyceae), two new species from the Mediterranean Sea based on morphological and molecular markers. Eur. J. Phycol. 46:327-41.

N'Yeurt, A. D. R. \& Payri, C. E. 2006. Marine algal flora of French Polynesia I. Phaeophyceae (Ochrophyta, brown algae). Crypt. Algol. 27:111-52.

N'Yeurt, A. D. R. \& Payri, C. E. 2010. Marine algal flora of French Polynesia III. Rhodophyta, with additions to the Phaeophyceae and Chlorophyta. Crypt. Algol. 31:3-205.

Okazaki, M., Pentecost, A., Tanaka, Y. \& Miyata, M. 1986. A study of calcium carbonate deposition in the genus Padina (Phaeophyceae, Dictyotales). Br. Phycol. J. 21:217-24.

Papadopoulou, A., Monaghan, M. T., Barraclough, T. G. \& Vogler, A. P. 2009. Sampling error does not invalidate the Yule-coalescent model for species delimitation. A response to Lohse (2009). Syst. Biol. 58:442-4.

Parks, D. H., Porter, M., Churcher, S., Wang, S., Blouin, C., Whalley, J., Brooks, S. \& Beiko, R. G. 2009. GenGIS: a geospatial information system for genomic data. Genome Res. 19:1896-904.

Paulay, G. \& Meyer, C. 2002. Diversification in the tropical Pacific: comparisons between marine and terrestrial systems. Integr. Comp. Biol. 42:922-34.

Pinzón-Navarro, S., Barrios, H., Múrria, C., Lyal, C. H. C. \& Vogler, A. P. 2010. DNA-based taxonomy of larval stages reveals huge unknown species diversity in neotropical seed weevils (genus Conotrachelus): relevance to evolutionary ecology. Mol. Phylogenet. Evol. 56:281-93.

Pons, J., Barraclough, T. G., Gomez-Zurita, J., Cardoso, A., Duran, D. P., Hazell, S., Kamoun, S., Sumlin, W. D. \& Vogler, A. P. 2006. Sequence-based species delimitation for the DNA taxonomy of undescribed insects. Syst. Biol. 55:594-609.

Posada, D. 2008. JModeltest: phylogenetic model averaging. Mol. Biol. Evol. 25:1253-6.

R Development Core Team. 2009. R: A Language and Environment for Statistical Computing. R Foundation for Statistical Computing, Vienna, Austria ISBN 3-900051-07-0. Available at: http:// www.R-project.org (accessed 11 December 2012).

Rambaut, A. \& Drummond, A. J. 2009. Tracer v1. Available at: http://beast.bio.ed.ac.uk/tracer (accessed 11 December 2012).

Rambaut, A. \& Drummond, A. J. 2011. TreeAnnotator version 1.6.2 [computer program]. Available at: http://beast.bio.ed. ac.uk (accessed 11 December 2012).

Riosmena-Rodríguez, R., Paul-Chávez, L., Hernández Carmona, G., López-Vivas, J. M. \& Casas Valdez, M. M. 2009. Taxonomic reassessment of the genus Padina (Dictyotales, Phaeophyta) from the Gulf of California. Algae 24:129-38.

Ronquist, F. \& Huelsenbeck, J. P. 2003. MRBAYES 3: Bayesian phylogenetic inference under mixed models. Bioinformatics 19:1572-4.

Salgado, L. T., Amado, G. M., Fernandez, M. S., Arias, J. L. \& Farina, M. 2011. The effect of alginates, fucans and phenolic substances from the brown seaweed padina gymnospora in calcium carbonate mineralization in vitro. J. Cryst. Growth 321:65-71.

Silberfeld, T., Leigh, J. W., Verbruggen, H., Cruaud, C., de Reviers, B. \& Rousseau, F. 2010. A multi-locus time-calibrated phylogeny of the brown algae (Heterokonta, Ochrophyta, Phaeophyceae): investigating the evolutionary nature of the "brown algal crown radiation”. Mol. Phylogenet. Evol. 56:659-74. 
Sites, J. W. \& Marshall, J. C. 2003. Delimiting species: a Renaissance issue in systematic biology. Trends Ecol. Evol. 18: $462-70$.

Sites, J. W. \& Marshall, J. C. 2004. Operational criteria for delimiting species. Annu. Rev. Ecol. Evol. Syst. 35:199-227.

Snirc, A., Silberfeld, T., Bonnet, J., Tillier, A., Tuffet, S. \& Sun, J.-S. 2010. Optimization of DNA extraction from brown algae (Phaeophyceae) based on a commercial kit. J. Phycol. 46: 616-21.

Spalding, M. D., Fox, H. E., Allen, G. R., Davidson, N., Ferdaña, Z. A., Finlayson, M., Halpern, B. S. et al. 2007. Marine ecoregions of the world: a bioregionalization of coastal and shelf areas. Bioscience 57:573-83.

Stamatakis, A. 2006. RAxML-VI-HPC: maximum likelihood-based phylogenetic analyses with thousands of taxa and mixed models. Bioinformatics 22:2688-90.

Stamatakis, A., Hoover, P. \& Rougemont, J. 2008. A rapid bootstrap algorithm for the RAxML web servers. Syst. Biol. 57:758-71.

Steininger, F. F. \& Rögl, F. 1984. Paleogeography and palinspastic reconstruction of the Neogene of the Mediterranean and Paratethys. Geol. Soc. Lond. Spec. Pub. 17:659-68.

Sun, Z., Hasegawa, K. \& Tanaka, J. 2008. A morphological study of Padina australis (Dictyotales, Phaeophyceae) from Hainan Island. China. J. Jpn. Bot. 83:261-8.

Tamura, K., Peterson, D., Peterson, N., Stecher, G., Nei, M. \& Kumar, S. 2011. MEGA5: Molecular evolutionary genetics analysis using maximum likelihood, evolutionary distance, and maximum parsimony methods. Mol. Biol. Evol. 28:27319.

Tanaka, T. \& Nozawa, K. 1962. Some notes on the genera Padina and Zonaria in the Southwestern Islands of Japan. Kagoshima Mem. Fac. Fish. 11:179-87.

Templeton, A. R., Crandall, K. A. \& Sing, C. F. 1992. A cladistics analysis of phenotypic associations with haplotypes inferred from restriction endonuclease mapping and DNA sequence data. III. Cladogram estimation. Genetics 132:619-33.

Tronholm, A., Leliaert, F., Sansón, M., Afonso-Carrillo, J., Tyberghein, L., Verbruggen, H. \& De Clerck, O. 2012. Contrasting geographical distributions as a result of thermal tolerance and long-distance dispersal in two allegedly widespread tropical brown algae. PLoS ONE 7:e30813.

Umezaki, I. \& Yoneda, Y. 1962. Morphological and embryonal studies of Padina japonica Yamada. Acta Phytotax. Geobot. 19:80 -91 .

Verbruggen, H., Tyberghein, L., Pauly, K., Van Nieuwenhuyse, K., Vlaeminck, C., Kooistra, W., Leliaert, F. \& De Clerck, O. 2009. Macroecology meets macroevolution: evolutionary niche dynamics in the marine green alga Halimeda. Glob. Ecol. Biogeogr. 18:393-405.

Wichachucherd, B., Liddle, L. B. \& Prathep, A. 2010. Population structure, recruitment, and succession of the brown alga, Padina boryana Thivy (Dictyotales, Heterokontophyta), at an exposed shore of Sirinart National Park and a sheltered area of Tang Khen Bay, Phuket Province, Thailand. Aquat. Bot. 92:93-8.

Wiens, J. J. 2007. Species delimitation: new approaches for discovering diversity. Syst. Biol. 56:875-8.

Womersley, H. B. S. 1987. The Marine Benthic Flora of Southern Australia. Part II. South Australian Government Printing Division, Adelaide, 481 pp.

Wynne, M. J. 1998. A study of Padina antillarum (Kützing) Piccone and a comparison with $P$. tetrastromatica Hauck (Dictyotales, Phaeophyta). Crypt. Algol. 4:271-89.

Wynne, M. J. \& De Clerck, O. 1999. First reports of Padina antillarum and P. glabra (Phaeophyta-Dictyotaceae) from Florida, with a key to the Western Atlantic species of the genus. $\mathrm{Ca}$ ribb. J. Sci. 35:286-95.

Yoshida, T. 1998. Marine Algae of Japan. Uchida Rokakuho Publishing Co, Tokyo, 1222 pp.

Yoshida, T., Nakajima, Y. \& Nakata, Y. 2000. Check-list of marine algae of Japan. Jpn. J. Phycol. 48:113-66.

\section{Supporting Information}

Additional Supporting Information may be found in the online version of this article at the publisher's web site:

Figure S1. Results of the GMYC species delimitation based on cox3 sequence data. (A) Ultrametric tree based on a Bayesian analysis with divergences estimated under a relaxed molecular clock using an uncorrelated lognormal (ULLN) model in BEAST and coalescent tree prior.

Figure S2. Results of the GMYC species delimitation based on $r b c \mathrm{~L}$ sequence data. (A) Ultrametric tree based on a Bayesian analysis with divergences estimated under a relaxed molecular clock using an uncorrelated lognormal (ULLN) model in BEAST and coalescent tree prior. (B) The corresponding lineage-through-time plot. The red vertical line indicates the ML transition point of the switch in branching rates, as estimated by a GMYC model. (C) Single-threshold likelihood solutions to the GMYC model.

Table S1. The distribution of Padina species based on literature data in Algaebase (Guiry and Guiry 2012).

Table S2. Collection and publication details, provisional morphospecies names, voucher numbers, Genbank accession numbers and main morphoanatomical features for the Padina specimens included in this study. In the morphological matrix, states of the the eight characters $(\mathrm{A}-\mathrm{H})$ were encoded following the code provided as attached comments in the first row. Character states written in red refer to specimens that were examined by us. Character states written in black refer to specimens that were encoded based on literature.

Table S3. List of the PCR and sequencing primers used in this study, with indication of annealing temperature and source of each primer.

Table S4. Summary of the data set built for divergence time inference analysis. A single concatenated sequence was built for each ESU. Details of each concatenated sequence (Genbank accession, voucher number, length).

Table S5. Basic properties and model parameters values as estimated with ModelTest for cox3, $r b c \mathrm{~L}$ and psaA alignments. L: alignment length (nt); CS: number of constant sites (nt); PI: number of parsimony-informative sites (nt); $\alpha$ : gamma-shape heterogeneity parameter; I: estimated proportion of invariant sites.

Table S6. Occurrence over ten Spalding's marine realms of the 60 ESUs (see Fig. 1 for geographic range of each realm) recognized with DNA-based algorithmic species delineation methods. 